\title{
The Unheared Voice of Truant Students: Implications for School Leaders
}

\author{
Mesfin Manaze \\ PhD Student, Department of Educational policy and Leadership \\ JigJiga University, Ethipia \\ E mail: mesfinmanaze [AT] gmail.com
}

\begin{abstract}
The objective of this study was to explore the possible factors, impacts and prevention mechanisms by school administrators of absenteeism among high school students in Yekatit 12 preparatory school of Addis Ababa City Administration. To achieve the objective of the study a qualitative approach was employed and data was collected from five students based on the number of days that they were absent from school. The main data collection methods employed were consultation of documents like the attendance sheet and records of the student on their absenteeism and in depth interview. Once the data was collected, it was transcribed and translated. Content analysis was used to find out the main themes emerging to answer the basic questions raised. Base on the analysis of the study, it was found out that substance abuse resulted from peer pressure; economic problems due to family separation and domestic chore burden were the main factors for students' absenteeism. The impact of absenteeism was also found to be huge in decreasing academic performance and results of the students as they miss lectures, demonstrations and class activities which are going to be marked including tests and quizzes. Though teachers and school administrators support was mentioned, it was not found to be at the level which is required to fully understand and help them not to dropout from Scholl. Based on the findings of the study, it was recommended that the school has to put in place a strict control of drugs and alcohol inside the school premise, guidance and counseling service of the school to be strengthened and to try to engage NGOs and other partners to assist economically poor students.
\end{abstract}

Keywords--- Truancy, absenteeism, School leadership

\section{INTRODUCTION}

Truancy is not a new problem in the field of education. In fact, truancy has been a persistent problem since compulsory education laws were put into effect in the 19th century (Clay, 2004). Despite the long history of concern over truancy, the issue continues to raise serious concern due to its correlation to a number of negative student outcomes such as academic failure, school dropout, and delinquent behavior (Epstein \& Sheldon, 2002; Mueller, Giacomazzi, \& Stoddard, 2006).

\section{STATEMENT OF THE PROBLEM}

There are studies linking student absenteeism to school dropout (Gerrard, Bruhans, \& Fair, 2003; Ruebel et al., 2001).These studies hold that absenteeism and truancy are risk factors for dropping out of school. Student absenteeism at schools is a major concern in Public high schools in Ethiopia including Yekatit 12 Preparatory School. Public high schools have explicit policies regarding mandatory attendance that states a student with five days of absentee will be expelled from the school on the basis of inadequate attendance of class. Despite the strict rules, absenteeism is an on-going problem in Ethiopian Public high schools. Again, despite the observed nature of the problem (chronic absenteeism from class in secondary schools), as to the best knowledge of the researcher, there are no published studies that assessed the possible causes, impacts and preventions of chronic absenteeism qualitatively though there are some quantitative studies. Thus, this study will try to explore the possible factors, impacts and prevention mechanisms by school administrators of absenteeism among high school students in Yekatit 12 preparatory school

Accordingly the study will try to answer the following questions:

1. What do students believe are the factors that put them on the path to truancy?

2. How their truant behavior does affect their academic performance?

3. How do students describe the support they get from school administrators? 


\section{SIGNIFICANCE OF THE STUDY}

Teachers and school administrators of Yekatit 12 will benefit from this study mainly as it will clearly inform them the experiences, effect of truancy and the help they seek from them directly from their students as the researcher promised to present the findings to the school community as per the arrangement of the school. Teachers and school administrators of Addis Ababa City Administration will also benefit from it if the findings can be presented in educational conferences involving them. Finally it may ignite other researchers to conduct the study in larger or different settings using the same or different methodology.

\section{DELIMITATION OF THE STUDY}

The study was delimited to Addis Ababa City Administration. Yeakatit 12 preparatory Scholl was only considered based on its proximity for the researcher and the existence of the problem in the school. Conceptually, the study was delimited to causes of truancy, its impacts and the support of teachers and school administrators to help students with truancy problem.

\section{LITERATURE REVIEW}

Truancy, commonly defined as a student's unlawful absence from school without parental knowledge or consent, is often referred to as a symptom of a much larger problem.

Often we find, when we dig deeper, that beneath truancy lies a wide variety of issues, ranging from children caring for younger siblings during school hours, performing various duties to provide for family needs, exposure to violence in the home, abuse and neglect (victimization), bullying and/or peer pressure at school, acting out behaviors and incorrigibility (Bell, Rosen, \& Dyblacht, 1994; Corville-Smith, Ryan, Adams, \& Dalicandro, 1998; Reid, 1999).

\section{Possible Causes of School Non-Attendance}

According to Zhang, Katsiyannis, Barrett, and Wilson (2007), the causes for truancy can be positioned within four major categories. These categories include family factors, school factors, economic influences, and student variables.

Family factors that may cause truant behavior include, but are not limited to parents' education, parental supervision, and household income. In a study on eighth and tenth grade student absenteeism, Henry (2007) correlates family factors with truant behavior.

Henry's study illustrates that the lower the father's education, the more likely the child is to commit truancy. The chance the child would commit truancy was even higher if the mother was a high school dropout. Additionally, Henry's work proves that the longer a child is unsupervised after school, the more likely that child is to become a truant; $29.9 \%$ of truants were unsupervised for five hours or more after school whereas only $11.3 \%$ of truants were never unsupervised after school. In a recent study on truant offenders in the juvenile justice system, Zhang, et al. (2007) linked truancy to household income. They established that minors that are first referred to the juvenile justice system tend to be more financially impoverished, with a relatively higher percentage of families making less than $\$ 15,000$ per year, than their regularly attending peers. That is, students are more likely to exhibit truancy if they live in families that gross less than $\$ 15,000$ annually.

School factors that may cause truant behavior include, but are not limited to school climate, class size, attitudes, ability to meet each student's diverse needs, and the school's discipline policy regarding truancy. According to Wilkins (2008), students that attend large schools may feel isolated or alienated in their school setting, so to escape these feelings they choose not to attend. These students do not feel comfortable, wanted, valued, accepted, or secure; they are lacking a connection to a trustworthy somebody within the school. In oversized classrooms, students' diverse needs, whether they are instructional, social, or a various other, cannot consistently be met and student-teacher relationships cannot be developed. This leads to a school climate and attitude in which each individual must fend for him. Henry (2007) solicits that $23 \%$ of truants choose to skip school because they do not feel safe in their school environment. Moreover, if a student does not feel comfortable, secure, or safe, and logically decides to skip school because location $\mathrm{x}$ is safer than the school, he is punished. Tobin (2009) suggests that imposing more serious punishments has worsened truant behavior; thus proving punishment to be counterproductive in the fight against chronic absenteeism.

Economic influences that may cause truant behavior include, but are not limited to living situation and student employment. Henry (2007) discerned in his study that $33.5 \%$ of high school truants did not live with their mother or father, $27.6 \%$ lived with their father only,

$19.8 \%$ lived with their mother only, and $14.4 \%$ lived with both parents. Therefore, the likelihood that a student would commit truancy increases when the student lives with only one parent, and increases anywhere between $5.9 \%$ to $13.7 \%$, if the child lives with either his mother or father. Moreover, Henry explains that students, who work more than 20 hours per week, greatly increase their chances of committing truancy. Of the truants he examined, 23.9\% worked 20 hours or more per week, whereas only $13.4 \%$ worked five or less hours per week.

Student variables that may cause truant behavior include, but are not limited to physical and mental health problems, substance abuse, drug use, perception of self, and detachment from school. DeSocio, et al. (2007) identifies physical and mental health issues as contributing towards school absenteeism. They suggest that truancy coexists with 
student and family mental health disorders and may be an indicator for an existing or emerging mental health disorder, including post-traumatic stress disorder, anxiety, depression, and/or substance abuse. Supporting evidence from Henry's study (2007) implicates students that use alcohol one or more times a month as $26.5 \%$ more likely to skip school than peers who do not use alcohol, and if the student drinks to a level of intoxication his likelihood of skipping school increases to $31.2 \%$. Moreover, $33.9 \%$ of the students who have been truant smoke cigarettes and $37.2 \%$ smoke marijuana at least once a month. Of equal importance, students that held lower perceptions about themselves were more likely to skip school than students who held higher perceptions of themselves. For example, students that answered "probably won't" graduate from high school and "definitely won't" attend college committed higher truant behavior at $44.5 \%$ and $30 \%$ respectively than their peers who answered "definitely will" graduate from high school and "definitively will" go to college at $15 \%$ and $12.1 \%$ respectively. Even more defining, DeSocio et al. (2007) indicate, that as many as 30\% of youth who are absent on a given school day are representative of school disengagement, or detachment. According to Henry (2007), students that exhibit school disengagement, lack commitment to the school, are poor achievers, and hold low aspirations for their futures (ibid).

\section{Possible Effects of Truancy}

Henry (2007) indicates that truancy's consequences are extensive, resulting in negative implications for multiple levels of society. In the short-term, truancy can predict maladjustment, poor academic performance, school dropout, substance abuse, delinquency, and teen-age pregnancy. In the long-term, evidence reveals truancy is a predictor of poor adult outcomes, including violence, marital instability, job instability, adult criminality, and incarceration. Moreover, truancy exerts a negative effect on community because of its correlation with delinquency, crime, and other negative adult outcomes.

\section{METHODOLOGY}

\section{Research Approach and Design}

As I was seeking to explore the central phenomenon of student absenteeism among Yekatit 12 high school students, a purposefully selected high school, I used a qualitative approach. Qualitative research, as described by Creswell (2007), is designed to explore a problem or issue in response to "a need to study a group or population, identify variables that can be measured, or hear silenced voices" (Creswell, 2007, pp. 40). By conducting a qualitative study, I believed that i would be able to hear the silenced voices of students identified with chronic absenteeism.

\section{Setting and Participants}

The research was be conducted Yekatiti 12 preparatory school within located in Gulele Sub city of Addis Ababa City Administration. This site was selected purposefully because it was the school in which truancy is a major issue affecting the schools administration as I confirmed it from the academic director and the Guidance and counselor before conducting the study. Its proximity to my residence was also considered as the data collection will require my immediate presence in the school if the informant students are free.

The participants of the study were five, three females and two male students selected purposefully based on the number of days they were absent from school. For this purpose I had gone through attendance files and informal communication with the guidance and councilor to identify the study participants.

Data Collection Procedure

The following major steps were taken to collect data for this study.

First, through informal discussion with guidance and councilor and the vice director for academics, I checked the prevalence of the problem in the school.

Second, after grabbing a formal support letter from my department I approached the school and the main principal gave me a permission to conduct the study and arranged the vice directors and the guidance and councilor to help me. It is from his office that I got the rule on absenteeism.

After a brief discussion with guidance and councilor and the vice director for academics, the guidance and councilor gave me the list of students with chronic absenteeism problem and I selected ten students who were absent for more than ten days in the first semester only for the study, five from each sex.

In our next meeting with the guidance and councilor, he told me that six students, three from each sex, had agreed to participate the students and brought them to me on the same day at break time and I briefed them with the objective of my study. The students also confirmed me their agreement for their participation and took an appointment with all according to their interest.

Finally, I conducted the interview with four of them according to the schedule we set. As two of the students were absent on our appointment, I was supposed to contact the guidance and councilor for arrangement of another appointment. With his unreserved help, I was able to get another chance to meet the one of the students and took an interview. Therefore, my study participants are five students, three girls and two boys. 
During the interview, the participants were informed to not to mention their name and their right to stop the interview any time if they feel discomfort. The interviews conducted lasted from 40 minutes to 1 hour and ten minutes. There were some probes made by me depending on the responses of the students. For the sake of security, I was also taking notes in case the recorder got any problem.

\section{Data Collection methods}

Two types of data collection methods were employed to gather information for the study document review and interview. The document review was made to select students appropriate for the study and to see the steps followed to help students with the problem and take appropriate action. Secondly, interview session was held with all the participants to deeply investigate the problem and get their insights. For this purpose interview questions with appropriate probes were prepared (see Appendices) for each of the respondents and the interviews were conducted in Amharic to make it comfortable for the participants to express their ideas fully.

\section{ETHICAL CONSIDERATION}

At the beginning of the study, participants were approached in person and get informed through the introductory letter and the Informed Consent Form about the objective of the research and that before each interview that they had the right to withdraw from the study at any time. They were also guaranteed that there will be no foreseeable risks for participating in the study. Potential students' identifiers such as students name and address were not included in data collection and participants' names are represented by pseudonyms to ensure confidentiality. All recorded conversations and written transcripts remained in the custody of the researcher throughout the study.

\section{BACKGROUND INFORMATION OF THE STUDY PARTICIPANTS}

For the sake of confidentiality, the five participants are given pseudo names as Senait, Kaleb, Frehiwot, Abel and Hana for Participant I, Participant II to Participant VI and a brief introduction of each will be presented as follows as it will help to further understand the analysis of their response.

\section{Participant I}

Participant I is a grade eleven female student of age 19. She was born and raised in Addis Ababa and lives with her family. Her current school is the third school that she joined for secondary education after she got expelled from her previous two schools, one private and one public, because of absenteeism. She still had more than ten days of absentee in first semester only.

\section{Participant II}

Participant II is a 20 years old boy currently attending his education at grade twelve. He was born and raised at Ziway town, south of the capital city, and came to attend his secondary education in Addis Ababa. Currently he is living with his extended family.

\section{Participant III}

Participant III is a 20 years old grade twelve female student. She was born and raised at Debrezeit town, $45 \mathrm{~km}$ from the capital in south east direction. She spent three years in this school. In the first year of her stay, she was living with her father only in Addis Ababa. But due to a disagreement with her father, she dropped out from school and went back to Debrezeit to her grandparents. Her mother is living abroad. The next year, with the help of her mother, she again joined school and by now she is living with her two younger sisters and her brother.

\section{Participant IV}

Participant IV is a 20 years old grade twelve student. He was born and raised in Addis Ababa. After his mother died when he was in grade eight, he started to live with his Aunt as his father also died when he was very infant. A year before last year, he came to this school and started grade eleven. But due to the work load and other disagreements with his aunt, he left home and started to live alone. For that reason he dropped out and started grade eleven again last year.

\section{Participant V}


Participant V is a 19 years old female student of grade twelve. She was born and raised at Assela town, west of Addis Ababa, and came to Addis after completing grade six there. Currently she is living with her grandparents and her two younger sister and brother.

\section{DATA ANALYSIS AND INTERPRETATION}

After the interviews were made, I transcribed all of them verbatim and finally translate them to English. Then the translated data were categorized thematically to come up with the results. Accordingly Substance abuse, economic problems and domestic chore burdens were found to be factors for students' truancy. The impact of truancy on their academic performance and the help they get from the Scholl administrators was also presented.

The three basic questions intended to be answered by the study were,

- What do students believe are the factors that put them on the path to truancy?

- How their truant behavior does affect their academic performance?

- How do students describe the support they get from school administrators?

Accordingly the analysis of the data based on the responses of the participants' in line with the main questions to be answered is presented as follows.

\section{MAIN CAUSES FOR THE PARTICIPANTS' TRUANCY}

Substance abuse: Substance abuse was mentioned by one student as a reason for being absent from school. The main substances indicated by the student include alcohol, cigarette and drug. She explained during the interview;

Mesfin: As you told me you were absent from school for more than ten days. What are the main reasons for you to be absent from school?

Senait: We go out to clubs at night and drink alcohol, and smoke cigarette and use drug. As we go back home very drunk, it will be very hard for me to get up early in the morning and go to school. For that reason I will be absent from school (participant I).

She also explained that she first started because of peer pressure and even got arrested for carrying drug in the school premise in her previous school. According to her, it is very common for students to smoke cigarette and drug in her current school:

Senait:... when I was at grade nine, there were my seniors friends who talk about being "cool" as they go out at night to clubs, drink alcohol and smoke drugs. So I started to think about it and started it ... I was arrested for carrying a drug at school, got dropped from school and sent to rehabilitation center at St. Paul hospital. In this school, it is common to see students using drugs in toilets or sport fields as there is no strict control except occasionally (Participant I).

Though they mentioned that they are not involved in substance use, all of the other participants also acknowledge students' substance use inside the school premise. Participant IV goes on explaining the following:

Abel: ... what I don't like about this school is that there are some students who behave very bad inside the class and use substance inside the school. Actually some of the teachers also smoke publicly cigarette in front of their students (Participant IV).

The issue of the teachers' behavior of smoking in front of their students was discussed by all the participants when they were asked to discuss the question about the things that they dislike most about their school. In addition Participant I had stated the following on the influence of the external environment in which the school is located as follows:

Mesfin: why do you think is that students are involved in substance and alcohol use at this school?

Senait: actually the surrounding environment of the school is very favorable if you want alcohol, cigarette or chat as there are many groceries and Chat selling shops around. Some students also skip from the school jumping the fence of the school to go these shops (Participant I).

Economic Problem: Three of the five participants in the research mentioned economic problem as a reason for truancy. These students had to cover the living expense of their family as they don't live with their parents and have other to support. Participant V stated the following: 
Hana: My parents are living in Asela town and I am living here with my grandparents. My grandparents are so old that they can't work and cover our living expense. So I try to bring money for the family ... I am a dancer and employed in a traditional restaurant around bole. Six days a week except Monday night, I have to work from 7 $\mathrm{pm}$ to $1 \mathrm{am}$. Besides I have to train from $4 \mathrm{pm}$ to $6 \mathrm{pm}$ to show new dances to our customers. It is really very tiresome and I can't get from my bed to go to school in the morning so I will stay home (Participant V).

Participant IV in his part explained to me the following for the question that I asked him about the main reason for his truancy:

\begin{abstract}
Abel: ... I was absent from school for more than thirty days in the first semester only. I am a taxi assistant and have to work regularly so that the driver will not replace me. First of all I have to work, most of the time, till 10 pm at night. Also i have to work regularly to get enough money for my living expense as I am living alone. So I can't come regularly to school. That is the only reason why I am absent from school (Participant IV).
\end{abstract}

He also explained to me that this was not the case till he finished his elementary school.

Mesfin: Is this is your case from elementary school or happened when you join secondary school?

\begin{abstract}
Abel; My mother died when I finish grade ten. As my father died when I was very infant, I don't know him. After my mother's death, I started to live with my aunt, and I left her home because there was a heavy duty that I had to carry out and also some other issues. So I left the home and couldn't go to school for two years as I couldn't cover my living and education expense. After two years I saved some money being a taxi assistant and started my education and still I am working it (Participant IV).
\end{abstract}

The reason for being truant is not different for Kaleb too. He told me the following;

Kaleb: I am living with my extended family; my parents live at Zeway town. Here my relatives also have no enough income to cover my living and education, so I have to work and cover it. So during day time I wash cars near Kechene Medhanialem church and at night I watch cars for my customers. Our agreement is to watch the cars till 8 am or $9 \mathrm{~m}$. So by the time I finish my duty, it will be very late to go to school and I will be absent. Even sometime I finish very early; I will be tired and fall asleep to go to school. But after working for three days, when I have enough money for one week, I will go to school and when my money is over, I will go back to my duty (Participant II).

Domestic Chore Burden: Domestic chore, which include watching and caring for younger members of a family was stated as a reason for being absent from school by one of the participants. Participant III explained the following:

Mesfin: you are absent from school for many days which even you may got expelled from school for doing so. Is there any reason why you are doing so?

Frehiwot: ... me and my two younger sisters and my brother are living with our grandmother. My grandmother is very old and sick that she can't work. I am responsible to care them, prepare their food, accompany them to schools especially my brother as he is very young and is in grade one. I always woke up very early like 4:30 am in the morning and start to prepare breakfast and lunch for my brother and sisters. One of my sisters also tries to help me sometimes but as she is very young if she don't woke up by her, I don't want to disturb her. So sometimes it will be very late for me to go school for me after I send them school or I will be tired and fall asleep. So I will stay home, get some rest and finish my work so that I can go school by tomorrow (participant III).

She explained to me that she don't have financial problem as her mother sends her enough money for living. But that is not enough to hire a house maid for them. Her father, after got divorced with her mother is not helping them.

\title{
11. IMPACT OF ABSENTEEISM ON ACADEMIC PERFORMANCE
}

All the five students participated in my study emphasize that the impact of absenteeism on their academic performance. When Participant I explained the issue, she stated the following:

Mesfin: Do you think that being absent from Scholl have impacts on your academic performance?

Senait: yes, of course.

Mesfin: what is the impact? Please explain it to me? 
Senait: if you are absent from class, you will miss the teachers' presentations, marked class works and tests given at that particular day. This all is going to have a very huge impact on your performance and lead you to finish the grade level with very bad cumulative average (Participant I). follows:

She further explained its impact by comparing her performance in elementary and secondary school as

Senait: When I was at elementary school, I was a very good student, attend class regularly and stood up to $5^{\text {th }}$ or $10^{\text {th }}$ from my class. My parents were also very happy with my results and give me prizes at the end of each semester for my performance. After I got in to this life and start to be absent from class, I finish every year with bad results most of the time in the bottom. This is how it affects your academic performance (Participant I).

Participant IV also adds the following when he explains the impact of absenteeism on academic performance and result:

Abel; the teachers at the beginning of the year tell us that our result will be composed of class activity, assignments, test and final examination. Most of the assessments like classwork and mini tests are done inside the class. So when you miss one class, it means you will also miss the marks assigned for classwork, participation and attendance. This will finally affect your result (Participant IV).

The others also agree with what is stated by their colleagues and even emphasize that a missed class is difficult to compensate. As four of the participants are very busy in their out school time, they stress that apart from the results, they are missing the main points that they should know. Participant II said the following:

Kaleb: As I am busy and don't have enough time to read, I miss a lot of knowledge because of missing class. Even I try to understand it by myself; it will be difficult especially for some subjects which need the teachers' explanation (participant II).

\section{SUPPORT AND ACTION OF THE SCHOOL}

During my interview, I had also asked the participants the support of the school for them and how actions are taken on students exhibiting repeated absenteeism. Though all of them agree that there is a some effort from teachers', especially home room teachers, and the schools administration, especially the guidance and councilor, they emphasize that there is a huge gap by the school's side in understanding and supporting truant students. Participant I said:

Senait: Most of the teachers do not want to ask and understand your reason for your deed. They simply mention your name and ask you to leave the class let alone helping you. The case is the same with the school administration. I think they gather monthly attendance from home room teachers, so at the end of the month they will come to your class and ask you to bring your parents ... they will talk with them and your parents will sign to take the responsibility for the case not to happen again and will go to class. I am not saying this is the case for all teachers (participant).

Participant IV also explained the case as follows:

Mesfin: Do you explain your reasons for being absent from school for your teachers and the school administration? What is their reaction and support to you?

Firehiwot: My home room teacher knows my case and tries to help at least not to dropout. But the case of some teachers is very amazing. The moment they see me, they say that I have no interest in education and better no to come to their class again and will me out of their class in front of my classmates. I will get very embarrassed and leave the class, what can I do? I will simply leave the class and wait outside till the next class (participant IV).

Participant V also shares the same idea with her colleagues and even explains the impact of such treatment as follows:

Hana: when most teachers say something that you don't like because of your absence without asking you the reason for doing so, sometime the idea of leaving the school and stopping education will come to your mind. Thanks to God some other teachers again will talk to you, give you advice and start to think staying in school. It is really very hard (Participant $\mathbf{V})$.

\section{FINDINGS AND DISCUSSION}


The purpose of this study was to find out the unheard reasons of truant students at Yekatit 12 preparatory school. The findings from this study are consistent with the literature about the main causes of truancy in schools. Consistent with the literature, students that participated in this study stated that the main reasons for truancy include substance abuse resulted from peer pressure, economic problem and issues at home which include supporting family in terms of domestic chores. The study also revealed that students with the truancy problem are not getting enough support from the school.

The analysis of the data revealed that drug abuse will cause truancy of students. The drug abuse for students mainly results from peer pressures at school and outside the school. Especially the practice of using substance in schools due to lose control of the school administration is worsening the case.

The analysis of the collected data from interview revealed that students' separation with their families had a direct impact on their truancy. This is mainly manifested by the economic problem students are facing when they leave alone or with the extended family. These students struggle for living and covering their living expensed had caused them t be absent from school.

Having a very heavy domestic chore responsibility was also found as a main reason for student's truancy. In their effort to support their families and young family members, students may end being truant because of being tired and losing an appetite for education.

Loose support from teachers and school administration was also found as a result from the data analysis. This in turn was having an impact on truancy as students feel a sense of "non belongingness" to school; they were tempted to lose an appetite to education and leave the school.

\section{CONCLUSIONS}

The three basic questions intended to be answered by the study were,

- What do students believe are the factors that put them on the path to truancy?

- How their truant behavior does affect their academic performance?

- How do students describe the support they get from school administrators?

Accordingly, based on the findings of the study, the following conclusions were reached;

- Peer pressure can lead to truancy: in most cases students are influenced by their peers on substance use and this is ultimately leading students to exhibit truant behavior.

- Family Separation will lead to students' truancy problem: students' separation with their families is putting economic problem on students which will leave them to work beyond their age including dangerous situations. Moreover their effort to survive is becoming labor exploitation which result a high level of fatigue and stress which results in students truancy.

- Insufficient support from the school leads to truancy: Insufficient understanding from all levels of the school structure from individual teachers to the school principal results in disliking the school environment and education. This will directly bring truancy.

\section{RECOMMENDATIONS}

The following are recommended based on the findings and conclusions from the study:

- $\quad$ The School should come up with a strong attendance mechanism

- There should be strict in school control by the school administration on substance use by students

- Together with the local government, the school environment should be cleaned from "chat" shops and groceries

- Teachers should help their students as much as possible

- The Guidance and Council service of the school should be strengthened

- The school together with the city administration should seek a mechanism to help poor students. Example: involving NGOs

\section{REFERENCES}

- Bell, A. J., Rosen, L. A., \& Dynlacht, D. (1994). Truancy intervention. Journal of Research and Development in Education, 27(3), 203-211.

- Clay, B. (2004). Reading, writing and reinforcement: A new look at truancy. Behavior Analysis Digest, 16, 1-2. 
- Corville-Smith, J., Ryan, B., Adams, G., \& Dalicandro, T. (1998). Distinguishing absentee students from regular attenders: The combined influence of personal, family and school factors. Journal of Youth Adolescence, 27(5), 629-637.

- Creswell, J. W. (2007). Qualitative inquiry and research design: Choosing among five approaches, second edition. Thousand Oaks, CA: SAGE.

- $\quad$ DeSocio, J., VanCura, M., Nelson, L. A., Hewitt, G., Kitzman, H., \& Cole, R. (2007). Engaging truant adolescents: Results from a multifaceted pilot intervention. Preventing SchoolFailure 51(3), 3-9.

- $\quad$ Epstein, J. L., \& Sheldon, S. B. (2002). Present and accounted for. Improving student attendance through family and community involvement. Journal of Educational Research, 95(5), 308-320.

- Gerrard, M.D., Burhans, A., \& Fair, J. (2003). Effective truancy prevention and intervention: A review of relevant research for the Hennepin County school success project. Wilder Research Center. Saint Paul, MN: Amherst Wilder Foundation.

- Henry, K. L. (2007). Who's skipping school: Characteristics of truants in 8th and 10th grade. Journal of School Health, 77(1), 29-35.

- Mueller, D., Giacomazzi, A., \& Stoddard, C. (2006). Dealing with chronic absenteeism and its related consequences: The process and short-term effects of a diversionary juvenile court intervention. Journal of Education for Students Placed at Risk, 11(2), 199-219.

- Reid, K. (1999). The self-concept and persistent school absenteeism. Truancy and school absenteeism. London, UK: Routledge.

- Ruebel, J. B., Ruebel, K. K., \& O'Laughlin, E. M. (2001). Attrition in alternative school programs: How well do traditional risk factors predict drop out from alternative schools? Contemporary Education, 72(1), 58-62.

- Wilkins, J. (2008). School characteristics that influence student attendance: Experiences of students in a school avoidance program. High School Journal, 91(3), 12-24.

- Zhang, D., Katsiyannis, A., Barrett, D. E., \& Wilson, V. (2007). Truancy offenders in the juvenile justice system: Examinations of first and second referrals. Remedial and SpecialEducation, 28(4), 244-256. 


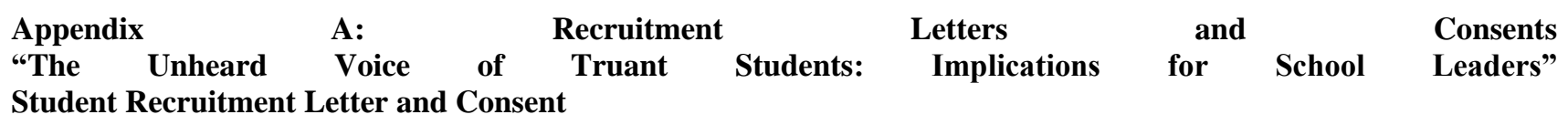

As a PhD student at Addis Ababa University, I am conducting research about truant student at your school for a partial fulfillment of the course Sociology of Education. To better understand about my research issue, I am going to interview students and school administrators. I would like you to be a part of this study. If you are interested and your parents/guardians are willing to let you participate in the study, I will host individual interviews in a quiet and comfortable place within the school setting. Each interview will take about 30-40 minutes, and follow-up interviews will be scheduled, as needed. With your permission, the interviews will be digitally recorded, to be used as transcripts by no one other than myself, as the researcher. I am committed to maintaining your confidentiality and comfort level. If you agree to participate, you will be asked to give a fictitious name in order to protect your identity. The use of a fictitious name will help to make sure you will never be associated with any presentations or publications related to this research. All information provided through the interview process will be kept confidential with exception to anything I am required to report by law. If you would prefer not to participate in this research project, it will in no way affect your services or support provided by the school. If you choose to participate, you have the right to decline any questions and the right to stop the interview at any time. Please complete and sign the included consent forms, keeping one for your records and return the second copy to me. Once I have received the signed form I will contact you to schedule an interview. If you have any questions about this study, please feel free to contact me, Mesfin Manaze, by email at mesfinmanaze@ gmail.comor by phone at 0913838924.

I thank you for your consideration.

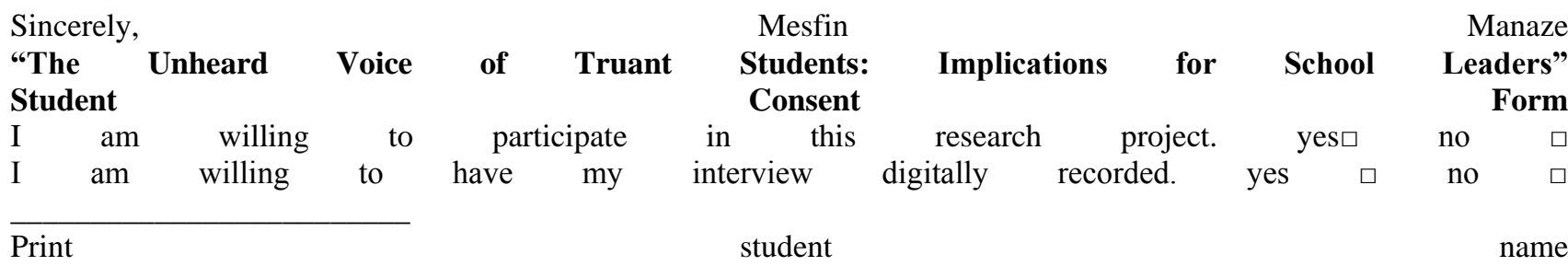

Student

Date 
Appendix B: Interview Questions

"The Unheard Voice of Truant Students: Implications for School Leaders" Tentative Student Interview Protocol

Date of Interview:

Time of Interview:

Location of Interview:

Name of Interviewer:

Name of Interviewee - pseudonym:

(Briefly describe the research\& interview procedures, ensure confidentiality, and remind the interviewee, he or she has the right to decline questions and/or the right to stop the interview at any time.)

Interview Questions: (Initial questions are to put the student at ease.)

- Tell me a little about yourself - How old are you? What do you like to do in your spare time?

- How long have you been a student at Yekatit 12 School?

○ How would you describe your school? What is best thing about your school? The worst?

- How would you describe your attendance at school?

- What are the reasons that made you to be absent from school?

○ Do you think that absenteeism have an impact on your academic performance? If so, how?

- How do your teachers and/or the school administrator(s) respond to your absences?

○ In what ways, if any, do you think your teachers and administrator(s) can support you in improving your attendance at school?

○ Is there anything else you would like me to know? 